\title{
What is the "normal" fetal heart rate?
}

Aim: There is no consensus about the normal fetal heart rate. Current international guidelines recommend for the normal fetal heart rate (FHR) baseline different ranges of 110 to 150 beats per minute (bpm) or 110 to $160 \mathrm{bpm}$. We started with a precise definition of "normality" and performed a retrospective computerized analysis of electronically recorded FHR tracings. Methods: We analyzed all recorded cardiotocography tracings of singleton pregnancies in three German medical centers from 2000 to 2007 and identified 78,852 tracings of sufficient quality. For each tracing, the baseline FHR was extracted by eliminating accelerations/decelerations and averaging based on the "delayed moving windows" algorithm. After analyzing 40\% of the dataset as "training set" from one hospital generating a hypothetical normal baseline range, evaluation of external validity on the other $60 \%$ of the data was performed using data from later years in the same hospital and externally using data from the two other hospitals. Results: Based on the training data set, the "best" FHR range was 115 or 120 to $160 \mathrm{bpm}$. Validation in all three data sets identified 120 to 160 bpm as the correct symmetric "normal range". FHR decreases slightly during gestation. Conclusions: Normal ranges for FHR are 120 to $160 \mathrm{bpm}$. Many international guidelines define ranges of 110 to $160 \mathrm{bpm}$ which seem to be safe in daily practice. However, further studies should confirm that such asymmetric alarm limits are safe, with a particular focus on the lower bound, and should give insights about how to show and further improve the usefulness of the widely used practice of CTG monitoring. 


\section{What is the "normal" fetal heart rate?}

Stephanie Pildner von Steinburg ${ }^{1}, \mathrm{MD}$, Anne-Laure Boulesteix ${ }^{1^{\star}, 2^{\star}}, \mathrm{PhD}, \mathrm{C}$. Lederer ${ }^{2} \mathrm{PhD}$, Stefani Grunow ${ }^{3^{*}}$, M. Sc., Sven Schiermeier ${ }^{4}$, MD, Wolfgang Hatzmann ${ }^{4}$, MD, Karl-Theodor M. Schneider ${ }^{1}$, MD, Martin Daumer ${ }^{2,3}, \mathrm{PhD}$ ( ${ }^{*}$ : affiliation during the study)

${ }^{1}$ Frauenklinik und Poliklinik der Technischen Universität München, Munich, Germany ${ }^{2}$ Sylvia Lawry Centre for Multiple Sclerosis Research, Munich, Germany ${ }^{3}$ Trium Analysis Online, Munich, Germany

${ }^{4}$ Frauenklinik, Universität Witten, Witten-Herdecke, Germany

\section{Corresponding author:}

Dr. Martin Daumer

Sylvia Lawry Centre for Multiple Sclerosis Research

Hohenlindener Str. 1

81677 München

Phone $\quad+498920602690$

Fax $\quad+4989206026951$

Email_daumer@slcmsr.org 


\section{Introduction}

Recording of fetal heart rate (FHR) via cardiotocography (CTG) monitoring is routinely performed as an important part of antepartum and intrapartum care. However, in several randomized trials it became evident that there is only limited efficacy in improving fetal outcome using CTG antenatally [16]. A detailed meta-analysis of available studies on the use of intrapartum cardiotocogram showed reduction of perinatal mortality by $50 \%$, but an increase of operative intervention by factor 2.5 [25]. One potential reason is the wide variability in clinical decision making associated with its use. Standardizing management of variant intrapartum FHR tracings was suggested to reduce this variability and to lead to improvement in fetal outcome [6]. In a recent Cochrane review no difference in outcome could be found when looking at potential improvements through the use of CTG monitoring, but, remarkably, the conclusion was different when computerized interpretation PeerJ reviewing PDF | (v2013:02:321:1:0:NEW 3 May 2013) 
of CTG traces was taken into account: "when computerized interpretation of the CTG trace was used, the findings looked promising" [28]. Therefore it seems natural to assume that further work on improving definitions and standardization by using computerized methods will further improve the monitoring systems. However, currently, there is not even agreement on the normal range of the baseline of the FHR, although, as Massaniev stated in 1996, "baseline rate provides valuable information on which we plan our further actions" [10].

The current international guidelines of the Fédération Internationale de Gynécologie et d'Obstétrique (FIGO) [18], based on consensus during the 1985 conference, recommend a normal range of the FHR from 110 to 150 beats per minute (bpm). The FIGO guidelines, despite some well-known shortcomings, "remain the sole broad international consensus document in FHR monitoring" [27]. This consensus replaced the former range of 120 to $160 \mathrm{bpm}$, as there was evidence pointing to worse fetal outcome for baselines higher than $160 \mathrm{bpm}$ [20]. Up to now, ranges such as 110 to $150 \mathrm{bpm}$ or 110 to $160 \mathrm{bpm}$ $[1,5,9,11,14,17,19,24]$ are also used, widely based on expert opinion rather than evidence.

This assessment of the situation and the existing "evidence base" is based on the following elements. We have published the plan to do the analysis and have publicly asked for feedback, We have done several literature searches mostly in pubmed, google scholar, the cochrane library and have collected publications listed in various versions of published CTG guidelines and standard textbooks. In total we have collected more than 100 papers related to the topic. We have asked opinion leaders in Germany, the UK and the US about awareness of any recent and ancient work that would need to mentioned. In addition, stimulated by the reviewer's comments, we have (March 2013) conducted a snow-ball search based on the original Manassiev paper, as well as a systematic search with the related topic of "electronic fetal monitoring". We did not find any published work PeerJ reviewing PDF | (v2013:02:321:1:0:NEW 3 May 2013) 
that would interfere with the findings in this manuscript.

Our aim was to first define what one should mean by "normal" fetal heart rate and then to give a data driven answer to this question, as a basis for the more complicated question about the right choice of "alarm limits". 


\section{Material and methods}

In order to reduce the probability of publishing false positive results, this study followed a strict analysis plan, published before onset of the analyses [4]. A similar methodology is now being recommended by ENCePP (www.encepp.org) of the European Medical Agency.

\section{CTG Database for exploration and validation}

From 2000 to 2007 CTG raw data were systematically collected from three hospitals: the two university hospitals "Technische Universität München" and "Witten-Herdecke" and the non-university hospital of Achern (Germany). "Technische Universität München" and "Witten-Herdecke" are tertiary care centers, while "Achern" is a primary care center. The work program and the corresponding contract were approved by the department of Obstetrics and Gynecology of the Technische Universität München and the legal department of the Technische Universität München and by the Ludwig Maximilian's University (cooperation contract in the context of Sonderforschungsbreich SFB 386, subproject B2 "Statistische Analyse diskreter Strukturen - Dynamische Modelle zur Ereignisanalyse, from April28, 2005).

The training data set consisted of the cardiotocograms recorded at "Technische Universität München" from 2000 to 2004. For validation three data sets were used: "Technische Universität München" from 2005 to 2006 for temporal validation, "Witten-Herdecke" from June 2005 to December 2007 and "Achern" from September 2001 to December 2005 for external validation.

We included all 87,510 FHR tracings recorded during the described period on CTG devices linked to the central server in the study, if they were derived from a singleton pregnancy. The included cardiotocograms were obtained both during labor in the delivery room and before onset of labor in the prenatal care unit, starting typically at gestational week 24 . The recordings were not necessarily longer than 30 minutes, as it was originally PeerJ reviewing PDF | (v2013:02:321:1:0:NEW 3 May 2013) 
planned, but a sensitivity analysis (data not shown) suggested, that this did not affect the results. 78,852 tracings demonstrated a sufficient signal quality, necessary for our analysis. For 13,015 CTG tracings collected between 20 and 42 weeks, data about gestational age were available, so that they could be used for analysis of association of FHR and gestational age.

\section{Investigated variables}

For each CTG tracing, the baseline heart rate was extracted from the FHR data coming from the CTG device at a rate of four measurements per second by excluding outlier measurements, eliminating accelerations or decelerations, and averaging based on the "delayed moving windows" algorithm [3]. These steps were automatically performed by the "Trium CTG Online ${ }^{\circledR}$ s software.

The basis for our analysis was the non-averaged baseline as computed by the CTG online algorithm [22] with one data point as statistical unit.

\section{Formulation of the normal fetal heart rate range}

We considered multiples of five as candidate FHR limits. For this purpose, we first divided the results for the FHR limits by five, rounded to the nearest integer and finally multiplied by five, eventually leading to an approximation of the exact FHR value by an integer ending with 0 or $5[9,13]$.

We chose the admissible widths of a candidate interval of normal FHR as 40 and $45 \mathrm{bpm}$. The candidate interval of normal FHR was selected by definition of intervals of 40 or 45 bpm width leading to similar numbers of measurements beyond the lower and upper limit. Further explanations concerning the mathematical optimization problem are provided in the previously published analysis plan [4]. 


\section{Validation Scheme and Statistical Methodology}

By analyzing the "training dataset" a hypothesis for the range of the normal fetal heart rate was built, fulfilling the analysis plan mentioned above. Validation data sets were not opened before the hypotheses were formed. Three independent statisticians did programming of these steps.

\section{Results}

\section{Patient characteristics}

We analyzed 45,915 (Training: 32,325, Validation: 13,590) CTG tracings from the university hospital "Technische Universität München" (2000-2006), 25,294 from the university hospital "Witten-Herdecke" and 7,643 from the non-university hospital of Achern. The pregnant women whose CTG tracings were included were treated antepartum in an in-patient or out-patient setting or they were admitted for delivery (with continuing or intermittent CTG surveillance). Characteristics of the patients delivered during the study period are summarized in Table 1 to give an impression of the population in the respective hospital. They show essentially similar results, but as expected they reveal slight differences consistent with regional characteristics (the small town Achern versus the city of Munich) and the high or low risk collective in tertiary and primary care centers. As an example, older and nulliparous women are more likely to deliver in the university hospitals. Also children with congenital malformations are born preferentially in the university hospitals, Munich even with a focus on heart malformations as the hospital cooperates with the German Heart Center in Munich for postnatal care of the babies.

A high percentage of the tracings were obtained ante partum or from women during first stage of labor as for example in "Technische Universität München" only 7,465 women (16.2\% of tracings) were delivered under CTG surveillance in the years of 2000 to 2006, PeerJ reviewing PDF | (v2013:02:321:1:0:NEW 3 May 2013) 
while 45,915 CTG tracings were recorded. In "Witten-Herdecke" 3,527 women (13.9\%) were delivered and 25,294 CTG tracings were recorded, in "Achern" there were 1,788 deliveries (23.4\%), but 7,643 CTG tracings were recorded. Our study comprises all weeks of pregnancies with analyzable CTG tracings, typically starting at 24 completed gestational weeks. But more than 75 percent of the CTG tracings were obtained from pregnancies older than 37 weeks.

\section{Fetal heart rate analysis}

The distribution of the FHR baseline measurements of the training data set over the whole range of possible frequencies is shown as a histogram in figure $1 \mathrm{~A}$, showing roughly the shape of a Gaussian distribution, but not the full symmetry. Distribution in steps of 5 bpm is summarized in Table 2 as a percentage of all measurements for the training data (Column 1).

The criterion for definition of the best interval is

$$
\arg \min _{i=1,5}\left(\widehat{F}\left(l_{\text {lower }}(i)\right)-\left(1-\widehat{F}\left(l_{\text {upper }}(i)\right)\right)^{2} .\right.
$$

(for further details see our analysis plan [4]).

Analyzing the training set, the selected interval of 40 to 45 bpm width was 115 to $160 \mathrm{bpm}$ (criterion: $\left.(0.0181-0.0321)^{2}=0.20 \cdot 10^{-3}\right)$. The criterion for the interval with 120 to 160 bpm was only marginally bigger (criterion: $\left.(0.0502-0.0321)^{2}=0.33 \cdot 10^{-3}\right)$ (Table 4 , Column 1), such that the lower bound, in contrast to the upper bound, is not stable. Hence the following hypotheses were formulated and tested during validation:

1. The upper limit of the FHR should be $160 \mathrm{bpm}$.

2. The lower limit should be either 115 or $120 \mathrm{bpm}$.

Results of each of the validation data sets and of a combination of all three of them revealed the range of 120 to $160 \mathrm{bpm}$ as the best interval (Figure 1B, Tables 2 and 3,

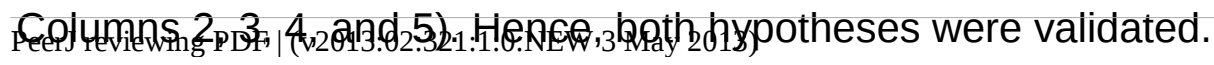


The mean FHR baseline plotted against gestational age is shown in Figure 2. Table 4 shows 95\% confidence intervals for mean FHR baseline in different gestational weeks. Regression analysis with the median FHR baseline as dependent variable and the gestational age (in weeks) as independent variable yielded a slope estimate of -0.378 $(p<0.001)$, meaning that the median FHR decreases on average by 0.4 bpm per week of pregnancy. The assumptions underlying the linear regression model were approximately fulfilled.

\section{Discussion}

Analyzing about 1.5 billion individual single baseline fetal heart rate measurements from 78,852 CTG tracings in three medical German centers, we found that "normal" ranges normality in a statistical sense - are 120 to160 bpm. By this data-driven definition of the normal FHR we aimed to generate a solid basis for the clinically important attempt to eventually further reduce the rate of false alarms in CTG monitoring in general and electronic decision support systems in particular. This might help to avoid unnecessary interventions such as cesarean sections. The FHR baseline in our analysis decreases slightly during gestation, in line with results of other groups $[15,23]$. There are well-known physiological changes in fetal development that are consistent with this empirical finding [29], essentially due to the increasing opposed effect of the sympathetic nervous system as gestational age increases.

Validation of the results in an independent data set is a crucial step to avoid the publication of false positive research findings [2,7]. Both temporal validation (based on data collected later than the training data) and external validation (based on data collected in another medical center), used in our study, are known to be essential [8]. Furthermore, the strict blind validation procedure was adopted and described in a detailed analysis plan in the pre-publication platform Nature Precedings [4] before starting the analyses. The results PeerJ reviewing PDF | (v2013:02:321:1:0:NEW 3 May 2013) 
about the normal range are very robust, indicating that neither the type of hospital which is potentially linked to special selection criteria for the pregnant women nor the time as measured roughly in 5-10 year intervals seems to play a role - an argument for the external validity of the findings in the exploratory part.

For user acceptance we used steps of $5 \mathrm{bpm}$ as possible borders of the normal FHR as recommended in the consensus meeting of the National Institute of Child Health and Human Development $[9,13]$. The width of the interval of 40 to $45 \mathrm{bpm}$ was traditionally used in many international guidelines. As we planned the study, we chose no other intervals, as narrowing of the interval would increase the false alarm rate and wider intervals could miss pathologic conditions of the fetus.

The upper limit of $160 \mathrm{bpm}$ raised concerns in the FIGO meeting in 1985, as Saling described abnormal findings in $24 \%$ of scalp blood analyses if the baseline was higher than 160 bpm [20]. It could be shown that the current FIGO guidelines based on computerized analyses of the CTG show a high sensitivity to detect fetal acidosis in case of a suspect or pathological classification of the baseline level. It may turn out that a modification of the normal ranges further improves sensitivity and specificity of fetal acidosis during labor [21]. Also, multivariate modeling involving fetal and maternal outcome data may improve evidence-based online decision support tools.

Data from a recently published study in a different context [23] is compatible with the findings of our exploratory analysis with a lower bound of 115 or 120 bpm for the gestational ages. Data for the 97th and 99th percentiles are not shown in this study. But shifting the lower limit to 120 will increase the number of false alarms whereas a lower limit of 115 will inevitably increase the risk to misinterpret maternal heart rates as fetal heart rate. This last problem has raised many concerns and discussions about technical solutions for differentiation of maternal and fetal heart rate, as fatal consequences for the fetus could occur [12]. The new German guideline [26] recommends therefore PeerJ reviewing PDF | (v2013:02:321:1:0:NEW 3 May 2013) 
simultaneous recording of fetal and maternal heart rate, technically possible either by maternal pulse oxymetry integrated in a CTG device or simultaneous ECG recording of mother and fetus.

As FHR tracings of prenatal care patients were included, our study population consists of a fraction of pregnancies remote from term, eventually resulting in higher baselines as suggested before. As our analysis according to gestational ages shows, the upper limit of $160 \mathrm{bpm}$ is valid for younger and for later gestational ages. A lower limit of $120 \mathrm{bpm}$ leads only near term to more false alarms since normal FHR decreases further, and is more appropriate, as discussed above, to avoid misinterpretation of maternal heart beat as FHR. There are no different guidelines for scoring cardiotocograms of early gestational ages as this would be too difficult in daily practice. Only computerized algorithms could use boundaries without rounding based on multivariate modeling and correlate these results to fetal outcome.

FIGO guidelines defined boundaries from 110 to $150 \mathrm{bpm}$, representing the approximately $0.6^{\text {th }}$ to $86^{\text {th }}$ percentile from our study. Current guidelines released by the American College of Obstetricians and Gynecologists [1], the National Institute of Child Health and Human Development [13], the Society of Obstetricians and Gynaecologists of Canada [24], the United Kingdom's National Institute for Health and Clinical Excellence [14], the Royal Australian and New Zealand College of Obstetricians and Gynaecologists [19] and the Japan Society of Obstetrics and Gynecology [17] define a very wide range of normal FHR with 110 to $160 \mathrm{bpm}$, representing the approximately $0.6^{\text {th }}$ to $96^{\text {th }}$ percentile. We raised concerns about the broad width of the range of $50 \mathrm{bpm}$ and the lower limit of $110 \mathrm{bpm}$. As these guidelines are in use for some years in many countries at the moment, we assume that this range is still safe for detection of fetal compromise. In contrast, specificity of the CTG for fetal acidosis becomes better. But safety-analyses should confirm this assumption. 
Our results have stimulated discussions within the corresponding German society "Deutsche Gesellschaft für Gynäkologie und Geburtshilfe" [5] having led to a recent update of the previous guidelines [26], based on data from the exploratory analysis. We hope that our study will trigger a process of continuous improvement of evidence based clinical decision making in fetal monitoring - perhaps a task to be triggered by the HTA working group of ENCePP (http://www.encepp.eu/structure/documents/ENCePPWGHTA_Mandate.pdf). 


\section{Acknowledgements}

We thank Nicholas Lack from the "Bayerische Arbeitsgemeinschaft für Qualitätssicherung" and Thomas Füsslin, Ortenau Klinikum Achern, for their support in providing information about the pregnancies at the Klinikum rechts der Isar and Ortenau Klinikum Achern. We thank Nadja Harner, Martina Günter and Michael Scholz for data management and technical support. We also would like to thank Erich Saling for helpful discussions and the speaker of Biomed-S and former speaker of the DFG-funded Sonderforschungsbereich SFB386 Prof. Dr. Fahrmeir, Ludwig-Maximilian's University, for continuous support. The comments of Marlene Sinclair and another anonymous reviewer have helped to further improve the manuscript. 


\section{References}

1. American Congress of Obstetricians and Gynecologists. Practice Bulletin No. 109: Intrapartum Fetal Heart Rate Monitoring: Nomenclature, Interpretation, and General Management Principles. Obstet Gynecol. 2009; 114: 192-202.

2. Daumer M, Held U, Ickstadt K, Heinz M, Schach S, Ebers G. Reducing the probability of false positive research findings by pre-publication validation experience with a large multiple sclerosis database. BMC Med Res Methodol. 2008; 8: 18, doi:10.1186/1471-2288-8-18.

3. Daumer M, Neiss A. A new adaptive algorithm to detect shifts, drifts, and outliers in biomedical time series. In: Kunert J, Trenkler G (eds.). Mathematical Statistics with Applications in Biometry. Lohmar, Deutschland: Josef Eul Verlag; 2001.

4. Daumer M, Scholz M, Boulesteix A-L, Pildner von Steinburg S, Schiermeier S, Hatzmann W, et al. The Normal Fetal Heart Rate Study: Analysis Plan and Amendment. Nat Precedings. 2007; doi:10.1038/npre.2007.980.1 available at http://precedings.nature.com/documents/980/version/2

5. Deutsche Gesellschaft für Gynäkologie und Geburtshilfe. Anwendung des CTG während Schwangerschaft und Geburt. [Application of CTG during pregnancy and delivery.] 2010; available at http://www.dggg.de/fileadmin/public_docs/Leitlinien/3-4-2-ctg-2010.pdf.

6. Downs T, Zlomke E. Fetal Heart Rate Pattern Notification Guidelines and Suggested Management Algorithm for Intrapartum Electronic Fetal Heart Rate Monitoring. Permanente J. 2007; 11: 22-8.

7. Ioannidis J. Why most published research findings are false. PLoS Med. 2005; 2(8): e124, doi:10.1371/journal.pmed.0020124. 
8. König I, Malley JD, Weimar C, Diener HC, Ziegler A. Practical experiences on the necessity of external validation. Stat Med. 2007; 26: 5499-511.

9. Macones GA, Hankins GD, Spong CY, Hauth J, Moore T. The 2008 National Institute of Child Health and Human Development workshop report on electronic fetal monitoring: update on definitions, interpretation, and research guidelines. J Obstet Gynecol Neonatal Nurs. 2008; 37: 510-5.

10. Manassiew N. What is the normal heart rate of a term fetus? BJOG. 1996; 103: 1269-73.

11. Manassiev N, Abusheika N, Victor-Olagundoye V, Johnstone M. What is the normal heart rate of a term fetus? J Obstet Gynaecol. 1998; 18: 442-4.

12. Murray ML. Maternal or fetal heart rate? Avoiding intrapartum misidentification. J Obstet Gynecol Neonatal Nurs. 2004; 33: 93-104.

13. National Institute of Child Health and Human Development Research Planning Workshop. Electronic fetal heart rate monitoring: Research guidelines for interpretation. Am J Obstet Gynecol. 1997, 177: 1385-90.

14. National Institute for Health and Clinical Excellence (NICE). Clinical Guideline 55: Intrapartum care: care of healthy women and their babies during childbirth. 2007, corrected 2008; available at www.nice.org.uk/nicemedia/live/11837/36275/36275.pdf

15. Nijhuis IJM, ten Hof J, Mulder EJH, Nijhuis JG, Narayan H, Taylor DJ et al. Numerical fetal heart rate analysis - nomograms, minimal duration of recording and intrafetal consistency. Prenat Neonat Med. 1998; 3: 314-22.

16. Pattison N, McCowan L. Cardiotocography for antepartum fetal assessment (Cochrane Review). In: The Cochrane Library, Issue 2, 2004. Chichester, UK: John 
Wiley \& Sons, Ltd.

17. Perinatal Committee of the Japan Society of Obstetrics and Gynecology. Guideline for intrapartum management based on FHR interpretation. Acta Obstet Gynaecol Jpn. 2009; 61: 1297-302.

18. Rooth G, Huch A, Huch R. FIGO News: Guidelines for the use of fetal monitoring. Int J Gynaecol Obstet. 1987; 25: 1159-67.

19. Royal Australian and New Zealand College of Obstetricians and Gynaecologists. Intrapartum Fetal Surveillance Clinical Guidelines. East Melbourne, Victoria: RANZCOG; 2006.

20. Saling E. Das Kind im Bereich der Geburtshilfe. Stuttgart, Deutschland: Georg Thieme Verlag; 1966.

21. Schiermeier S, Pildner von Steinburg S, Thieme A, Reinhard J, Daumer M, Scholz M, et al. Sensitivity and specificity of intrapartum computerised FIGO criteria for cardiotocography and fetal scalp pH during labour: multicentre, observational study. BJOG. 2008; 115: 1557-63.

22. Schindler T. Delayed Moving Window Algorithm for Online Cardiotocogram Analysis - A Comparison of Computerized CTG Analysis. Aachen, Deutschland: Mainz Verlag; 2002.

23. Serra V, Bellver J, Moulden M, Redman CWG. Computerized analysis of normal fetal heart rate pattern throughout gestation. Ultrasound Obstet Gynecol. 2009; 34: 74-9.

24. Society of Obstetrics and Gynaecologists of Canada. Fetal health surveillance: Antepartum and Intrapartum Consensus Guideline. J Obstet Gynaecol Can. 2007; 29: S3-56. 
25. Vintzileos AM, Nochimson DJ, Guzman ER, Knuppel RA, Lake M, Schifrin BS. Intrapartum electronic fetal heart rate monitoring versus intermittent auscultation: a meta-analysis. Obstet Gynecol. 1995; 85: 149-55.

26. Deutsche Gesellschaft für Gynäkologie und Geburtshilfe. Anwendung des CTG während Schwangerschaft und Geburt. [Application of CTG during pregnancy and delivery.] 2012; available through www.dggg.de

27. Diogo Ayres-de-Campos, Joao Bernardes, Twenty fice years after the FIGO guidelines for the use of fetal monitoring: time for a simplified approach?, Intl. Journal of Gynecology and Obstetrics 110, 2019, 1-6

28. Grivell RM, Alfirevic Z, Gyte GML, Devane D. Antenatal cardiotocography for fetal assessment. Cochrane Database of Systematic Reviews 2012, Issue 12. Art. No.: CD007863. DOI: 10.1002/14651858.CD007863.pub3

29. Karolina Afors and Edwin Chandraharan, Use of Continuous Electronic Fetal Monitoring in a Preterm Fetus: Clinical Dilemmas and Recommendations for Practice, Journal of Pregnancy, Volume 2011 (2011), Article ID 848794, doi: $10.1155 / 2011 / 848794$ 


\section{Figure 1}

Histogram of baseline fetal heart rate values

A, training data, B, validation data, C, all data. Red bars comprise $25^{\text {th }}$ to $75^{\text {th }}$ percentile, red and green ones $12.5^{\text {th }}$ to $87.5^{\text {th }}$ percentile, red, green and yellow bars $5^{\text {th }}$ to $95^{\text {th }}$ percentile and all bars except white ones comprise $2.5^{\text {th }}$ to $97.5^{\text {th }}$ percentile. 
A
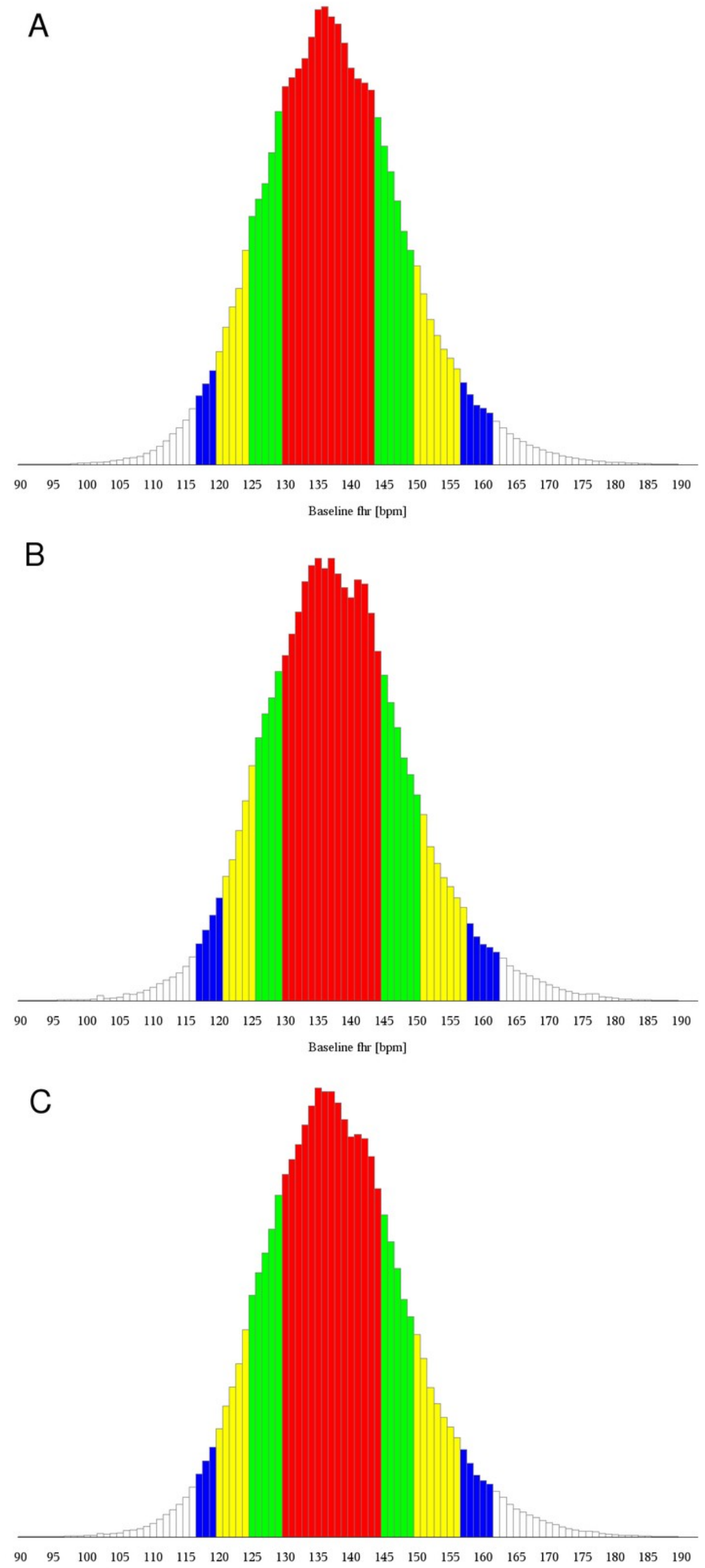

PeerJ reviewing PDF | (v2013:02:321:1:1:0:NEW 


\section{Figure 2}

Quantile bands of FHR plotted against gestational age

FHR (bpm) is plotted against gestational weeks from 20 to 42 . Red colours comprise $25^{\text {th }}$ to $75^{\text {th }}$ percentile, red and green ones 12.5 th to $87.5^{\text {th }}$ percentile, red, green and yellow colours $5^{\text {th }}$ to $95^{\text {th }}$ percentile and all colours comprise $2.5^{\text {th }}$ to $95.5^{\text {th }}$ percentile.

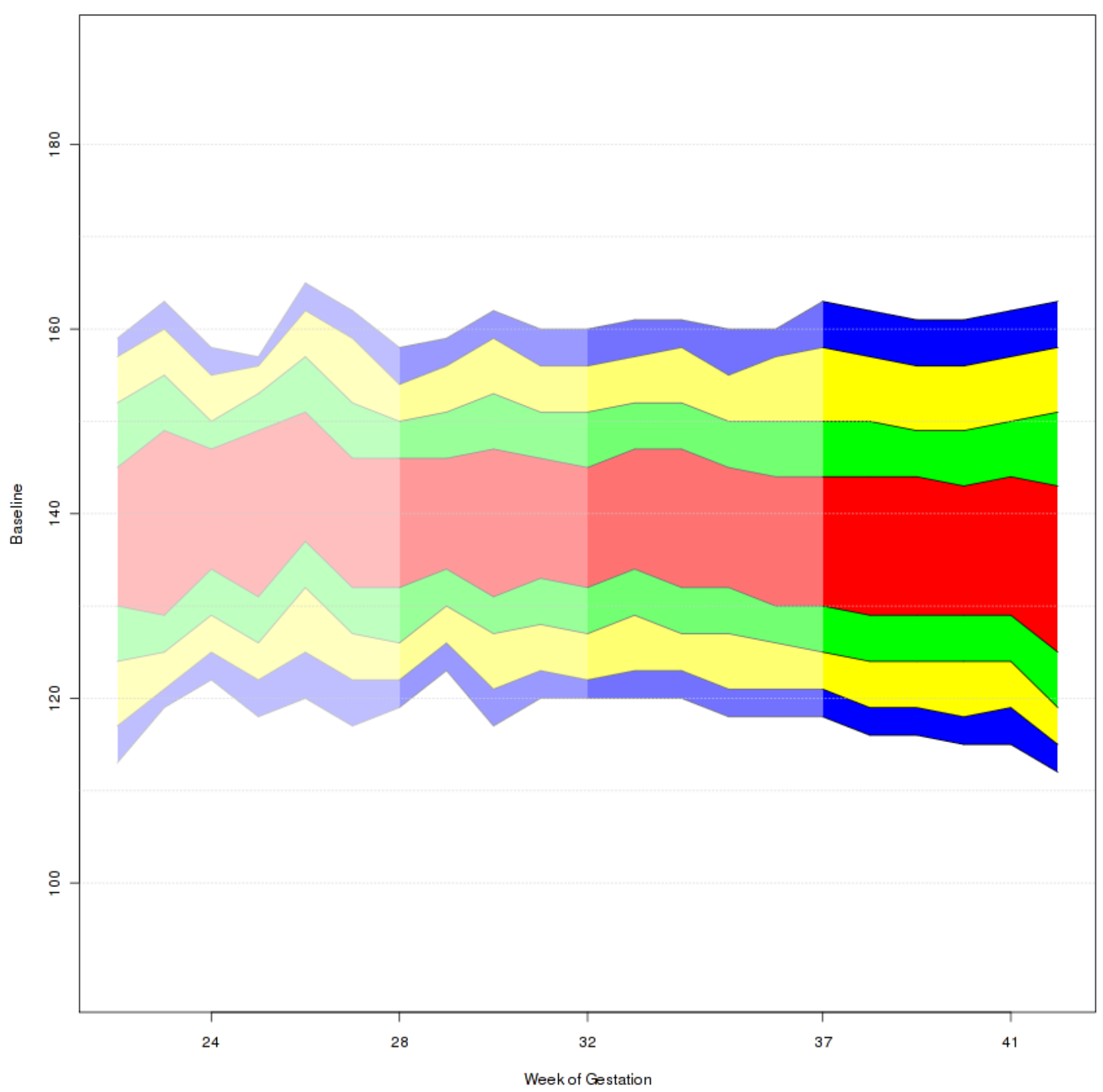




\section{Table $\mathbf{1}_{\text {(on next page) }}$ \\ Patient characteristics}

Description of patient characteristics. n/a, data not available or quality not sufficient; *, via ICD-10 coding. 


\begin{tabular}{|c|c|c|c|c|c|c|}
\hline & \multicolumn{2}{|l|}{ Characteristics } & $\begin{array}{l}\text { Training } \\
\text { TUM } \\
2000-2004\end{array}$ & $\begin{array}{c}\text { Validation I } \\
\text { TUM } \\
2005-2006\end{array}$ & $\begin{array}{c}\text { Validation II } \\
\text { WH } \\
06 / 2005-2007\end{array}$ & $\begin{array}{c}\text { Validation III } \\
\text { A } \\
09 / 2001-2005\end{array}$ \\
\hline & & & $\mathrm{n}(\%)$ & $\mathrm{n}(\%)$ & $\mathrm{n}(\%)$ & $\mathrm{n}(\%)$ \\
\hline & Number of delivered women & & 5,366 & 2,323 & 3,542 & 1,788 \\
\hline & Cardiotocogram recorded during & delivery & $5,184(96.6)$ & $2,281(98.2)$ & 3,527 (99.6) & $\mathrm{n} / \mathrm{a}$ \\
\hline \multirow{5}{*}{ 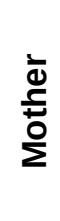 } & Maternal age & $<20 \mathrm{~J}$ & $88(1.6)$ & $38(1.6)$ & $105(3.0)$ & $78(4.5)$ \\
\hline & & $20-29 \mathrm{~J}$. & $1,707(31.9)$ & $744(32.0)$ & $1,440(40.7)$ & $739(42.6)$ \\
\hline & & 30-39 J. & $3,249(60.8)$ & $1,371(59.0)$ & $1,857(52.4)$ & $866(49.9)$ \\
\hline & & $\geq 40 \mathrm{~J}$. & $302(5.6)$ & $169(7.3)$ & $140(4.0)$ & $51(2.9)$ \\
\hline & Nulliparous women & & $2,387(44.7)$ & $986(42.5)$ & $1,477(41.7)$ & $458(27.9)$ \\
\hline \multirow{7}{*}{$\frac{\mathbb{d}}{\stackrel{D}{\Phi}}$} & Gestational age at delivery & $\mathrm{MW} \pm \mathrm{STD}$ & $38.3 \pm 3.0$ & $38.2 \pm 3.0$ & $38.4 \pm 2.4$ & $38.8 \pm 3.0$ \\
\hline & Normal delivery & & $3,058(57.1)$ & $1,237(53.3)$ & $1,992(56.2)$ & $1,050(58.4)$ \\
\hline & Forceps extraction & & $88(1.6)$ & $14(0.6)$ & $75(2.1)$ & $0(0)$ \\
\hline & Vacuum extraction & & $263(4.9)$ & $131(5.6)$ & $71(2.0)$ & $137(7.6)$ \\
\hline & Elective Cesarean & & $824(15.4)$ & $405(17.4)$ & 774 (21.9) & $289(16.1)$ \\
\hline & Secondary Cesarean & & $1,118(20.9)$ & $535(23.0)$ & $630(17.8)$ & $321(17.9)$ \\
\hline & Tocolysis during delivery & & $1,177(21.9)$ & $584(25.2)$ & 645 (18.2) & $\mathrm{n} / \mathrm{a}$ \\
\hline \multirow{5}{*}{ 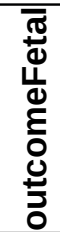 } & Male & & $2,799(52.2)$ & $1,177(50.7)$ & $1,799(50.2)$ & $927(51.8)$ \\
\hline & Female & & $2,567(47.8)$ & $1,146(49.3)$ & $1,743(49.8)$ & $861(49.2)$ \\
\hline & Birthweight (g) & $\mathrm{MW} \pm \mathrm{STD}$ & $3,157 \pm 727$ & $3,138 \pm 731$ & $3,263 \pm 631$ & $3,393 \pm 475$ \\
\hline & Congenital malformation* & & $\mathrm{n} / \mathrm{a}$ & $75(3.2)$ & $125(3.5)$ & $15(0.8)$ \\
\hline & Congenital heart malformation* & & $\mathrm{n} / \mathrm{a}$ & $36(1.5)$ & $11(0.3)$ & $\mathrm{n} / \mathrm{a}$ \\
\hline
\end{tabular}




\section{Table $2_{\text {(on next page) }}$}

Distribution of the fetal heart rate in the training and validation sets

Displayed is the number of singular fetal heart rate recordings under or above the given limits of fetal heart rate as a percentage of all measurements. 


\begin{tabular}{|c|c|c|c|c|c|}
\hline & $\begin{array}{l}\text { Training } \\
\text { TUM } \\
2000-2004\end{array}$ & $\begin{array}{l}\text { Validation I } \\
\text { TUM } \\
2005-2006\end{array}$ & $\begin{array}{l}\text { Validation II } \\
\text { WH } \\
06 / 2005-2007\end{array}$ & $\begin{array}{l}\text { Validation III } \\
\text { A } \\
09 / 2001-2005\end{array}$ & Validation I - III \\
\hline \multicolumn{6}{|l|}{ Lower limit } \\
\hline$<100$ bpm & $0.13 \%$ & $0.15 \%$ & $0.08 \%$ & $0.17 \%$ & $0.12 \%$ \\
\hline < 105 bpm & $0.26 \%$ & $0.26 \%$ & $0.15 \%$ & $0.37 \%$ & $0.24 \%$ \\
\hline$<110$ bpm & $0.62 \%$ & $0.64 \%$ & $0.40 \%$ & $0.78 \%$ & $0.57 \%$ \\
\hline$<115$ bpm & $1.81 \%$ & $1.79 \%$ & $1.24 \%$ & $1.68 \%$ & $1.53 \%$ \\
\hline$<120$ bpm & $5.02 \%$ & $4.90 \%$ & $3.54 \%$ & $4.45 \%$ & $4.21 \%$ \\
\hline \multicolumn{6}{|l|}{ Upper limit } \\
\hline$>145$ bpm & $23.26 \%$ & $23.81 \%$ & $27.84 \%$ & $22.33 \%$ & $25.22 \%$ \\
\hline$>150$ bpm & $12.56 \%$ & $13.13 \%$ & $16.09 \%$ & $12.04 \%$ & $14.16 \%$ \\
\hline$>155$ bpm & $6.51 \%$ & $6.96 \%$ & $8.67 \%$ & $6.23 \%$ & $7.53 \%$ \\
\hline$>160$ bpm & $3.21 \%$ & $3.55 \%$ & $4.35 \%$ & $3.11 \%$ & $3.79 \%$ \\
\hline$>165$ bpm & $1.47 \%$ & $1.76 \%$ & $2.00 \%$ & $1.51 \%$ & $1.80 \%$ \\
\hline$>170$ bpm & $0.68 \%$ & $0.78 \%$ & $0.92 \%$ & $0.70 \%$ & $0.82 \%$ \\
\hline
\end{tabular}




\section{Table 3 (on next page)}

Calculation of the criterion for definition of the best interval in the training and validation data sets.

Square of difference between upper and lower tail of the distribution ([i] ), as shown in Table 3. All values have to be multiplied with $10^{-3}$. The best criterion for each data set is marked in bold letters. 


\begin{tabular}{|c|c|c|c|c|c|}
\hline & $\begin{array}{l}\text { Training } \\
\text { TUM } \\
2000-2004 \\
\end{array}$ & $\begin{array}{l}\text { Validation I } \\
\text { TUM } \\
2005-2006 \\
\end{array}$ & $\begin{array}{l}\text { Validation II } \\
\text { WH } \\
\text { 06/2005-2007 }\end{array}$ & $\begin{array}{l}\text { Validation III } \\
\text { A } \\
09 / 2001-2005 \\
\end{array}$ & Validation I - III \\
\hline $110-150$ & 14.24 & 15.60 & 24.62 & 12.69 & 18.48 \\
\hline $110-155$ & 3.46 & 3.99 & 6.83 & 2.97 & 4.85 \\
\hline $115-155$ & 2.21 & 2.68 & 5.51 & 2.07 & 3.61 \\
\hline $115-160$ & 0.20 & 0.31 & 0.97 & 0.20 & 0.51 \\
\hline $120-160$ & 0.33 & 0.18 & 0.07 & 0.18 & 0.02 \\
\hline $120-165$ & 1.26 & 0.98 & 0.24 & 0.86 & 0.58 \\
\hline
\end{tabular}




\section{Table 4(on next page)}

Distribution of FHR baseline during gestation

A. 95\% confidence intervals for mean FHR baseline are displayed for intervals of several gestational weeks. All pairwise comparisons are significant $(\mathrm{p}<0.01)$ with both t-test and Mann-Whitney-test. The comparisons between gestational age of $>=37$ and other groups are the most significant. B. 95\% confidence intervals for mean FHR baseline within the group of gestational age of 37 weeks or more. 


\begin{tabular}{lllll}
\hline Gestational age & $\mathrm{n}$ & \multicolumn{3}{l}{$95 \%$ confidence interval } \\
\hline$<28$ & 1230 & 140.7538 & - & 141.9422 \\
\hline $28-<32$ & 1059 & 139.1587 & - & 140.3843 \\
\hline $32-<37$ & 2248 & 138.1575 & - & 138.9322 \\
\hline$>=37$ & 8478 & 136.0104 & - & 136.4295 \\
\hline
\end{tabular}

\begin{tabular}{lllll}
\hline Gestational age & $\mathrm{n}$ & \multicolumn{3}{l}{$95 \%$ confidence interval } \\
\hline 37 & 1090 & 136.7176 & - & 137.8588 \\
\hline 38 & 1793 & 135.5575 & - & 136.4720 \\
\hline 39 & 1962 & 135.9786 & - & 136.8404 \\
\hline 40 & 2325 & 135.2181 & - & 136.0158 \\
\hline 41 & 1199 & 135.9135 & - & 137.0438 \\
\hline 42 & 109 & 133.2492 & - & 137.8009 \\
\hline
\end{tabular}

